\title{
Optimal overlays for preservation of concrete in cold climate: decision-making by the method of fuzzy comprehensive evaluation combined with AHP
}

\author{
Zhipeng $\mathrm{Li}^{\mathrm{i}^{\dagger}}$, Yudong Dang ${ }^{2 \dagger}$, Zhen Tang ${ }^{3,4}$, Ning Xie ${ }^{5}$, Shuang $\mathrm{Lu}^{3,4^{*}}$ and Xianming Shi ${ }^{*}$ (D)
}

\begin{abstract}
Overlays have been extensively employed as an effective preservation or rehabilitation tool to extend the service life of concrete bridges and pavements, especially concrete slabs suffering from salt scaling and abrasion. However, limited attention has been paid to the durability and performance of these overlays which can be jeopardized when they are exposed to freeze/thaw and wet/dry cycles, deicer applications, studded tires, and their coupled effects. Various overlays feature different engineering properties, and they might be only effective in specific service environments but not in others, and research is lacking to examine their ability to adapt to different environments. This study subjected five overlay products on concrete slabs to the combined action of freeze/thaw (F/T) and wet/dry (W/D) cycles with periodical exposure to either $15 \mathrm{wt} . \% \mathrm{NaCl}$ solution or $15 \mathrm{wt} . \% \mathrm{MgCl}_{2}$ solution, to simulate the typical field scenarios in an accelerated manner. The bond strength, splitting tensile strength, and abrasion resistance of the overlaid concrete slabs were tested to evaluate the effectiveness of various overlays against the deicer scaling and the abrasion by studded tires. Based on the experimental data, this study demonstrated a multi-criteria decision-making method, fuzzy comprehensive evaluation (FCE) combined with analytic hierarchy process (AHP), for the selection of optimal overlays in three different service scenarios (e.g., states of Washington and Oregon [USA] and British Columbia [Canada]). The analysis results indicate that one epoxy overlay exhibited the comprehensively best performance and could be a promising candidate in all three given scenarios, another polymer overlay took second place, while the adaptability of the three cement-based overlays varied in different environments.
\end{abstract}

Keywords: Concrete preservation, Salt scaling, Deicer, Fuzzy comprehensive evaluation, Analytic hierarchy process, Multi-criteria decision making

\footnotetext{
*Correspondence: hitlu@163.com; xianming.shi@wsu.edu

†Zhipeng Li and Yudong Dang contributed equally to this work.

${ }^{1}$ Department of Civil \& Environmental Engineering, Washington State

University, P. O. Box 642910, Pullman, WA 99164-2910, USA

${ }^{4}$ School of Civil Engineering, Harbin Institute of Technology,

Harbin 150090, Heilongjiang, China

Full list of author information is available at the end of the article
}

(C) The Author(s) 2021. Open Access This article is licensed under a Creative Commons Attribution 4.0 International License, which permits use, sharing, adaptation, distribution and reproduction in any medium or format, as long as you give appropriate credit to the original author(s) and the source, provide a link to the Creative Commons licence, and indicate if changes were made. The images or other third party material in this article are included in the article's Creative Commons licence, unless indicated otherwise in a credit line to the material. If material is not included in the article's Creative Commons licence and your intended use is not permitted by statutory regulation or exceeds the permitted use, you will need to obtain permission directly from the copyright holder. To view a copy of this licence, visit http://creativecommons.org/licenses/by/4.0/. 


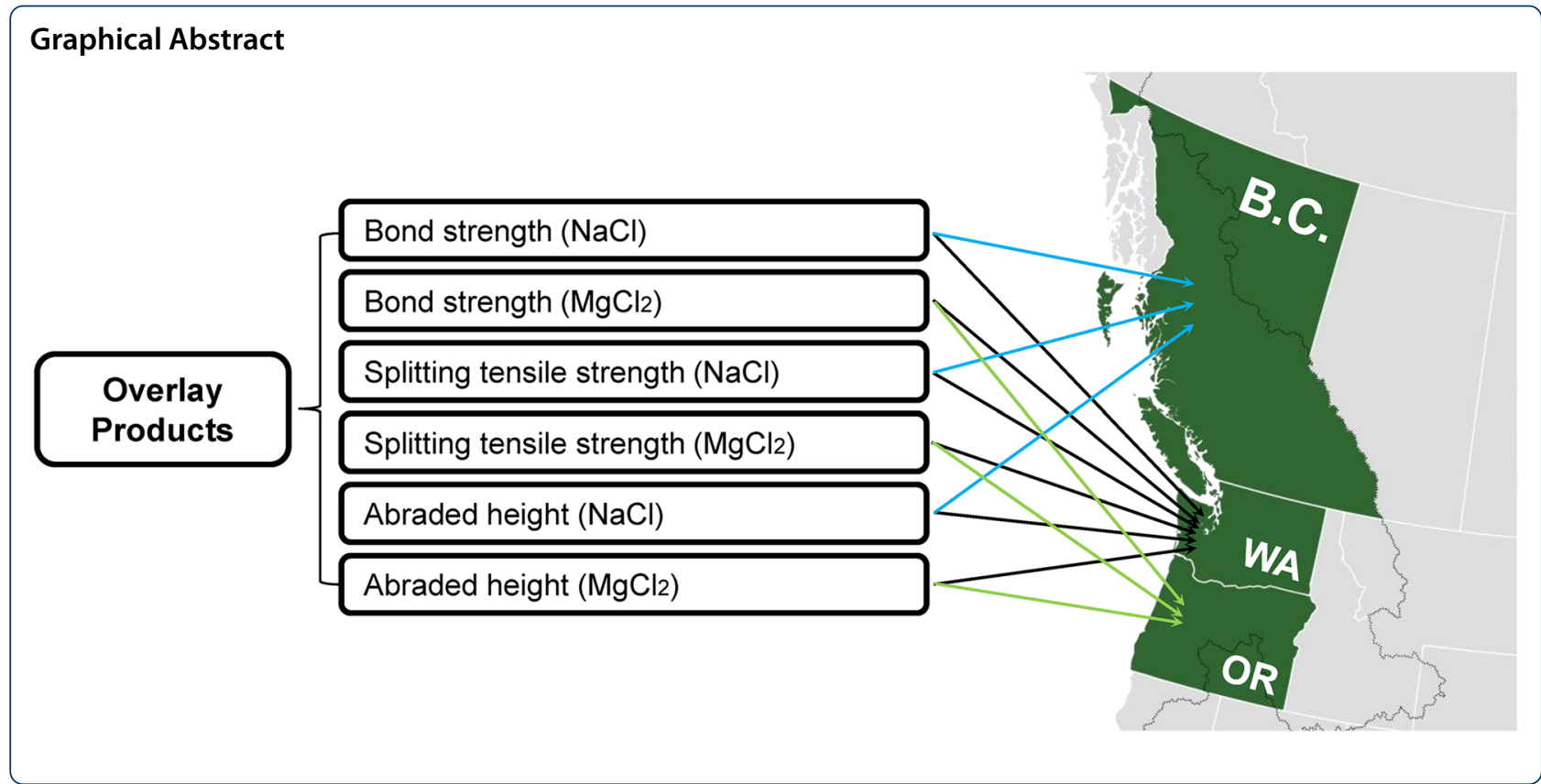

\section{Introduction}

Deicing and anti-icing chemicals (a.k.a., deicers) are increasingly used as effective tools to enable winter road maintenance operations in cold-climate regions; yet their deleterious impacts on the concrete infrastructure, motor vehicles, and the natural environment are becoming a growing concern. According to the Federal Highway Administration [6], the U.S. spends approximately $\$ 2.3$ billion annually for snow and ice control operations on highways, and the indirect costs of such operations (due to damages to infrastructure and natural environment) add at least $\$ 5$ billion annually. Chloride-based salts, especially sodium chloride $(\mathrm{NaCl})$, magnesium chloride $\left(\mathrm{MgCl}_{2}\right)$, and calcium chloride $\left(\mathrm{CaCl}_{2}\right)$, remain the most commonly used freezing point depressants in deicer products [5]. For all the roadways in the U.S. (highways, local roads, etc.), approximately 20 million tons of $\mathrm{NaCl}$ based road salt are applied for snow and ice control every year [3].

Chlorides-based deicers show significant corrosive effects on steel reinforcement embedded in concrete $[10,19,31]$, and they also pose significant risks to the performance and durability of concrete pavements, bridges, etc. $[9,15,24,37]$. Deicing salts can not only physically attack portland cement concrete (PCC) to result in its damage with the common symptoms of "scaling, map cracking, or paste disintegration" [27], but also chemically attack PCC and reduce its integrity and strength by reacting with cement paste and/or aggregates $[16,20$, 35]. For instance, Verian and Behnood [29] reported that different degrees of degradation in pavement concrete specimens occurred when exposed to different deicing salts $\left(\mathrm{MgCl}_{2}, \mathrm{CaCl}_{2}\right.$, and $\left.\mathrm{NaCl}\right)$ and freeze/thaw or wet/ dry cycles. Among the three deicers, $\mathrm{CaCl}_{2}$ induced the most destructive damage to concrete, whereas $\mathrm{NaCl}$ resulted in the deepest intrusion of chloride but the least damage. Reiterman and Keppert [17] studied the effect of different chloride salts on the residual mechanical properties, final ingress of chloride, and surface scaling during freezing-thawing cycles, and their conclusions agreed well with those of Verian and Behnood [29]. In contrast, Dang et al. [4] found that deicer scaling of concrete in $3 \mathrm{wt} . \% \mathrm{NaCl}$ solution was mainly manifested as surface scaling and notable reductions in Young's modulus and compressive strength, whereas "deicer scaling" of concrete in $3 \mathrm{wt} . \% \mathrm{MgCl}_{2}$ solution featured no visible surface scaling yet substantial reduction in splitting tensile strength. Deicer-induced attack to concrete would be intensified when in conjunction with other mechanical and environmental loads [23]; the deterioration of concrete matrix by exposure to deicing salts is likely to foster the ingress of moisture, oxygen, and other aggressive agents (e.g., chloride anions) onto the surface of rebar or dowel bar and thus promote their corrosion in concrete $[19,28]$.

Overlays have been proven effective among the array of tools to protect concrete bridge decks (or pavements) from their service environment (freeze-thaw cycling, studded tires, etc.) and preserve their integrity $[8,18$, 32]. Overlays can also be used to prevent the ingress of chloride salts [7]. For example, Abo Sabah et al. [1] employed a new type of "green" concrete to protect the 
normal concrete substrate, this top layer of "green" concrete overlay featured considerably higher compressive strength $(153.64 \mathrm{MPa}$ at 90 days) than the bottom normal concrete $(50.76 \mathrm{MPa}$ at 90 days), the bond strength (36.2 MPa at 90 days) was also desirable, and the service life of this double-layered composite was much longer than the single-layered normal concrete slab. Wang et al. [30] investigated the employment of crumb rubber-modified epoxy-based overlays to repair concrete slabs and they illustrated the great potential of this kind of overlay. Freeseman et al. [7] evaluated two types of overlays and reported that the epoxy-based overlays showed much better chloride resistance. These overlays can also be used to rehabilitate aged concrete infrastructure in the field, and the selection of the most appropriate or cost-effective one(s) greatly depends on the type and level of deterioration of the base concrete. A comprehensive study by Janssen [11] revealed that the use of asphalt concrete overlays "does not prevent the progression of D-cracking in PCC; instead, some overlay thicknesses accelerate the deterioration". In light of over 25 years of case histories, Kuhlmann [13] concluded that "latex-modified cement systems are applicable wherever adhesion, durability, and compatibility with the base concrete are required". A field study by Chanvillard et al. [2] suggested that a thin bonded, steel-fiber-reinforced concrete overlay can effectively rehabilitate old concrete pavements.

The vast majority of existing studies have only focused on the mechanical performance and abrasion resistance of overlays, and there is still insufficient research on how the durability of overlays on bridge decks (or concrete pavements) might be affected by their exposure to deicers and vehicular traffic in the field environment. Once the degraded overlay fails to meet the protection requirements, a new round of rehabilitation would be needed in order to provide timely preservation of the underlying deck (or pavement), incurring additional social, economic, and environmental costs. In addition, little research has been reported on how to quantitatively select the optimal preservation treatment (e.g., overlay) for concrete infrastructure, when there are multiple performance parameters of interest and various service conditions of interest.

In this context, the main objectives of this work were to investigate the effects of chloride-based deicers on concrete bridge decks and to identify the best overlay products to mitigate such undesirable effects in the states of Washington and Oregon (USA) and British Columbia (Canada). This work presents the accelerated laboratory evaluation of overlays for protecting concrete bridge decks from the combined attack by freeze/thaw $(\mathrm{F} / \mathrm{T})$ and wet/dry (W/D) cycles with periodical exposure to chloride-based deicers. Furthermore, we demonstrate a multi-criteria decision-making method, coupling fuzzy comprehensive evaluation (FCE) with analytic hierarchy process (AHP), to assess the adaptability of five selected overlays in the three use cases. FCE is a multifactor decision-making method $[14,38]$ that has been applied in many fields, because this method can be employed to quantify the fuzzy factors by calculating their "final scores" and then determine the best option. When FCE is applied, AHP is usually followed to quantify the decision weight of selected factors to enable more scientific and reliable assessment [14]. The decision based on the combined use of FCE and AHP is better than that based on AHP alone, because the decision weights in the latter case are more objective and may result in an unreasonable decision if lacking the relevant experience and knowledge. More details are provided in the following sections.

\section{Experimental \\ Materials}

An ASTM specified C150-07 Type I/II GU portland cement used in this study was purchased from Diamond Mountain, MT. The coarse aggregate (with a maximum size of $9.5 \mathrm{~mm}$ ) and fine aggregate (clean and natural silica sand with a maximum size of $4.75 \mathrm{~mm}$ ) were purchased from the JTLGroup (Belgrade, MT). A chemical agent, triethanolamine (TEA), was used as an admixture for accelerating the development of concrete strengths at early age. The nanoclay used to prepare overlay was a polysiloxane-modified montmorillonite featuring a bulk density of $0.251 \mathrm{~g} / \mathrm{cm}^{3}$ and an aspect ratio of $200 \sim 400$. The carbon microfiber used in this study was KRECA chop C-103 $\mathrm{T}$ provided by Kureha (Tokyo, Japan), $3 \mathrm{~mm}$ in length and $18 \mu \mathrm{m}$ in filament diameter, featuring a desirable high tensile intensity of $670 \mathrm{MPa}$ and tensile elastic modulus of $30 \mathrm{GPa}$. Table 1 presents the mix proportioning of the concrete substrate slabs.

All concrete slab specimens were fabricated in the laboratory as follows. Firstly, the fine and coarse aggregates were dry-mixed for $5 \mathrm{~min}$ (without water), then the cement was added and mixed into aggregates for 5 min until a homogeneous mixture was obtained. In the

Table 1 Mix proportioning of concrete $\left(\mathrm{kg} / \mathrm{m}^{3}\right)$

\begin{tabular}{ll}
\hline Materials & Proportion \\
\hline Cement & 407 \\
Water & 223.9 \\
TEA & 0.2035 \\
Fine aggregate & 655 \\
Coarse aggregate & 1022 \\
Air-entraining agent (MicroAir 111) & 0.02442 \\
\hline
\end{tabular}


meantime, TEA was fully dissolved into tap water, then poured into the dry mixture and fully blended to reach the desired consistency. The fresh concrete mixture was cast into slab molds in size of 20 in $\times 15$ in $\times 4$ in $(50 \mathrm{~cm}$ $\times 37.5 \mathrm{~cm} \times 10 \mathrm{~cm}$ ) and covered with a plastic film for $24 \mathrm{~h}$ to avoid the evaporation of moisture. After demolding, the concrete slab samples were moved to a standard curing condition $\left(22 \pm 2{ }^{\circ} \mathrm{C}\right.$ with a relative humidity of $95 \pm 3 \%$ ) and cured for 27 days and 55 days for further evaluation, respectively. The properties of fresh and hardened concrete are provided in Table 2.

\section{Overlays}

In this study, three cement-based overlays (silica fume modified, latex-modified, and microfiber/nanoclayreinforced mortar overlays) and two polymer overlays (T48: polysulfide epoxy overlay and PPC-1121: polyester polymer concrete overlay) were evaluated, and the basic information of these overlays is listed in Tables 3 and 4 , respectively. The corresponding casting processes of the cement-based overlays are depicted in Fig. 1. These overlay products were identified as the effective products various state DOTs in the norther climate used to protect their bridge decks, according to a nationwide survey of practicing engineers [21].

For cement-based overlays, after curing at standard condition $\left(22 \pm 2^{\circ} \mathrm{C}\right.$ with a relative humidity of $\left.95 \pm 3 \%\right)$ for 27 days, the concrete slabs were dried at $23 \pm 1{ }^{\circ} \mathrm{C}$ and relative humidity of $50 \%$ for another $24 \mathrm{~h}$ before further processing. A wire brush was used to polish the concrete slabs until the paste on the surface of the slabs was removed (see Fig. 1a). The polished slabs were then wetted and a wooden frame was installed around the slabs (see Fig. 1b) for casting overlays. When the placing of cement-based overlays in thickness of 1 in $(2.5 \mathrm{~cm})$ finished (see Fig. 1c), a plastic sheet (see Fig. 1d) was employed to cover the fresh overlays for $24 \mathrm{~h}$ to avoid the evaporation of water. After removing the sheet, the slabs-overlays composites were transferred to a standard condition $\left(22 \pm 2^{\circ} \mathrm{C}\right.$ with a relative humidity of $\left.95 \pm 3 \%\right)$ for another 27 days for further testing. The whole curing age for concrete slabs was 56 days and the curing age for cement-based overlays was 28 days.

For polymer overlays, the concrete slabs were cured at the same standard condition for 54 days, and then

Table 2 Properties of fresh and hardened concrete

\begin{tabular}{ll}
\hline Slump, mm & 210 \\
Air content of fresh concrete, \% & 2.9 \\
Pore volume, \% & 10.14 \\
Compressive strength at 28d, MPa & 30.69 \\
Splitting tensile strength at 28d, MPa & 6.38 \\
\hline
\end{tabular}

dried and polished as similar to the procedure of processing cement-based overlays. Since a dry surface was required for casting polymer overlays, the surface of the polished concrete slabs was kept dry until applying these polymer overlays. Then the concrete slabs/polymer overlays composites were transferred to a normal laboratory room $\left(22 \pm 2^{\circ} \mathrm{C}\right)$ for $24 \mathrm{~h}$ hardening for further testing. Same as cement-based overlay/slab composites, the whole curing age for concrete slabs under polymer overlays was 56 days; even though the curing age for polymer overlays was only 1 day, due to its quick curing process.

\section{Deicing scaling procedure: exposure to freeze/thaw and wet/dry cycles and deicers}

By following the SHRP H205.8 test method entitled "Test Method for Rapid Evaluation of Effects of Deicing Chemicals on Concrete" with minor modifications, the laboratory measurements of changes to concrete substrate-overlay composites through freeze/thaw and wet/dry cycles in the presence of deicers were conducted. The SHRP H205.8 test evaluates the effects of chemical deicing formulations and freeze/thaw cycles on the structural integrity of small test specimens of non-air-entrained concrete, by quantitatively evaluating the degradation of the concrete specimens through the measurements of weight loss.

Before the beginning of F/T-W/D cycles, the concrete slab-overlays composites were dried at $40^{\circ} \mathrm{C}$ for $24 \mathrm{~h}$ and then immersed into a plastic box containing deicer solutions for another $24 \mathrm{~h}$ to saturate the pores. Based on our previous research [36] and the research of Sutter et al. $[25,26]$, the concentration of both $\mathrm{NaCl}$ and $\mathrm{MgCl}_{2}$ solution was fixed at $15 \%$ for potential comparison. Then, the plastic box was placed into the freezer for $12 \mathrm{~h}$ at $-17.8 \pm 2.7^{\circ} \mathrm{C}$ to initiate the repetitive $\mathrm{F} / \mathrm{T}$ W/D cycles. For concrete substrate-overlay composites, the average temperature in the middle of the samples was about $5.0 \pm 1.0^{\circ} \mathrm{C}$ which is slightly higher than the temperature of the freezer. Such discrepancies in the actual temperature and the target temperature could be explained by the latent heat in the concrete specimens. An analogy could be also made to explain the difference between the air temperature and the temperature inside a concrete deck in the service environment. Subsequently, the composite slabs (along with the plastic box) were moved to the laboratory environment at $23 \pm 1.7^{\circ} \mathrm{C}$ with relative humidity ranging from 45 to $55 \%$ until the ice in the plastic box was completely thawed, then the composite slabs were transferred to ambient laboratory conditions and dried in air for $4 \mathrm{~h}$ to finish W/D cycles. After repeating 10 times of F/W-W/D cycle, the cylinder 


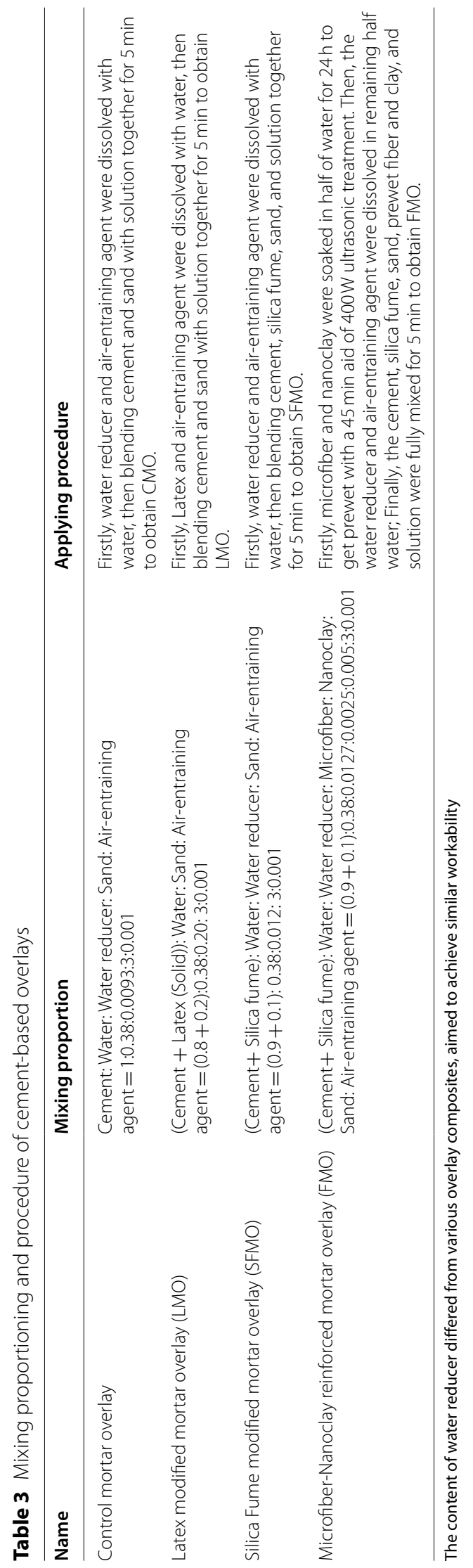


Table 4 Mixing proportioning and procedure of polymer overlays

\begin{tabular}{|c|c|c|c|}
\hline Name (Manufacturer) & Type and the main constituent & Mixing proportion & Applying procedure \\
\hline \multirow[t]{2}{*}{ T-48 (Transpo Industries, Inc.) } & Polymer (Resin) & Primer: Resin & $\begin{array}{l}\text { Two coats of the Resin were applied } \\
\text { to the surface of the concrete using a } \\
\text { paintbrush before the application of } \\
\text { the Overlay }\end{array}$ \\
\hline & $\begin{array}{l}\text { Polymer (Resin, Hardener, and } \\
\text { powder) }\end{array}$ & $\begin{array}{l}\text { Overlay: } \\
\text { Resin } \\
1 / 2 \text { Hardener by the volume of } \\
\text { Resin } \\
11.55 \text { lbs Powder by } 1 \mathrm{~L} \text { of resin. }\end{array}$ & $\begin{array}{l}\text { Resin and Hardener were thoroughly } \\
\text { mixed to guarantee the final full } \\
\text { hardening. Before hardening, the } \\
\text { fresh mixture was fully mixed with } \\
\text { powder products immediately. The } \\
\text { entire mixture was then poured onto } \\
\text { the concrete slab and evenly coated } \\
\text { on the surface with a flat spoon. The } \\
\text { overlay was left to cure for } 20 \text { min } \\
\text { and then a layer of aggregate was } \\
\text { applied to the base coat after } 20 \text { min } \\
\text { of curing until complete coverage } \\
\text { was achieved. Then the overlay was } \\
\text { left to cure for } 24 \mathrm{~h} \text {, after which the } \\
\text { excess aggregate was brushed off. }\end{array}$ \\
\hline
\end{tabular}

PPC-1121 (Kwik Bond Polymers, Inc.)
Polymer (Resin, promoter, and initiator)

Polymer (Resin, catalyst, accelerator, and aggregate)
Primer: Resin

$32.3 \mathrm{~g}$ Promoter by $1 \mathrm{~L}$ of resin

$32.3 \mathrm{~g}$ Initiator by $1 \mathrm{~L}$ of resin

Resin and promoter were thoroughly mixed and then incorporating the initiators, two coats of the mixture were applied to the surface of the concrete slab with a paintbrush and allowed to cure for $24 \mathrm{~h}$ (before application of the overlay layer.

Resin and catalyst were thoroughly mixed and then incorporating into

Overlay:

Resin

$1.6 \%$ Catalyst by the volume of resin $4 \%$ Accelerator by the volume of resin

$14 \mathrm{lbs}$. Sand and Rock Mix by $1 \mathrm{~L}$ the accelerator. The entire mixture was blended with the sand and rock and stirred together until obtaining a homogenous mixture. The entire mixture was then scooped onto the concrete slab and spread evenly. The overlay was left to cure for $24 \mathrm{~h}$. Different from T-48, no surficial aggregate broadcast was required.

samples were drilled from the slabs and the properties of these cylinder samples (such as bond strength, splitting tensile strength, and abrasion resistance) were tested which was detailed in the following sections.

\section{Bond strength}

Bond strength testing of overlays was performed following the ASTM C1583/C583-04 entitled "Standard Test Method for Tensile Strength of Concrete Surfaces and the Bond Strength or Tensile Strength of Concrete Repair and Overlay Materials by Direct Tension (Pull-off Method)". Before the testing, a steel brush was used to clean the surface of the overlays to guarantee the adhesion between joints and overlays. The fracture may happen at the overlays, the concrete substrate, or their interface, and ASTM C1583 specified that the bond strength was determined by the fracture mode that firstly occurred three times. In this study, the bond strength for each composite slab was tested many times and the most frequent fracture mode was selected to determine the bond strength.

\section{Splitting tensile strength}

Splitting tensile (ST) strength testing was performed following ASTM C496/C496M-11 entitled "Standard Test Method for Splitting Tensile Strength of Cylindrical Concrete Specimens". The size of cylindrical concrete substrate-overlays composite specimens was 2 in $\times 4$ in $(5 \mathrm{~cm} \times 10 \mathrm{~cm})$ that drilled from the composite slabs directly. The thickness of overlays in this cylinder was 1 in $(2.5 \mathrm{~cm})$ and the concrete substrate was 3 in $(7.5 \mathrm{~cm})$. The loading speed was controlled at $2 \mathrm{MPa} / \mathrm{min}$ and the splitting tensile strength could be calculated by the following equation:

$$
\text { ST Strength }=2 \mathrm{P} /(\pi D l)
$$



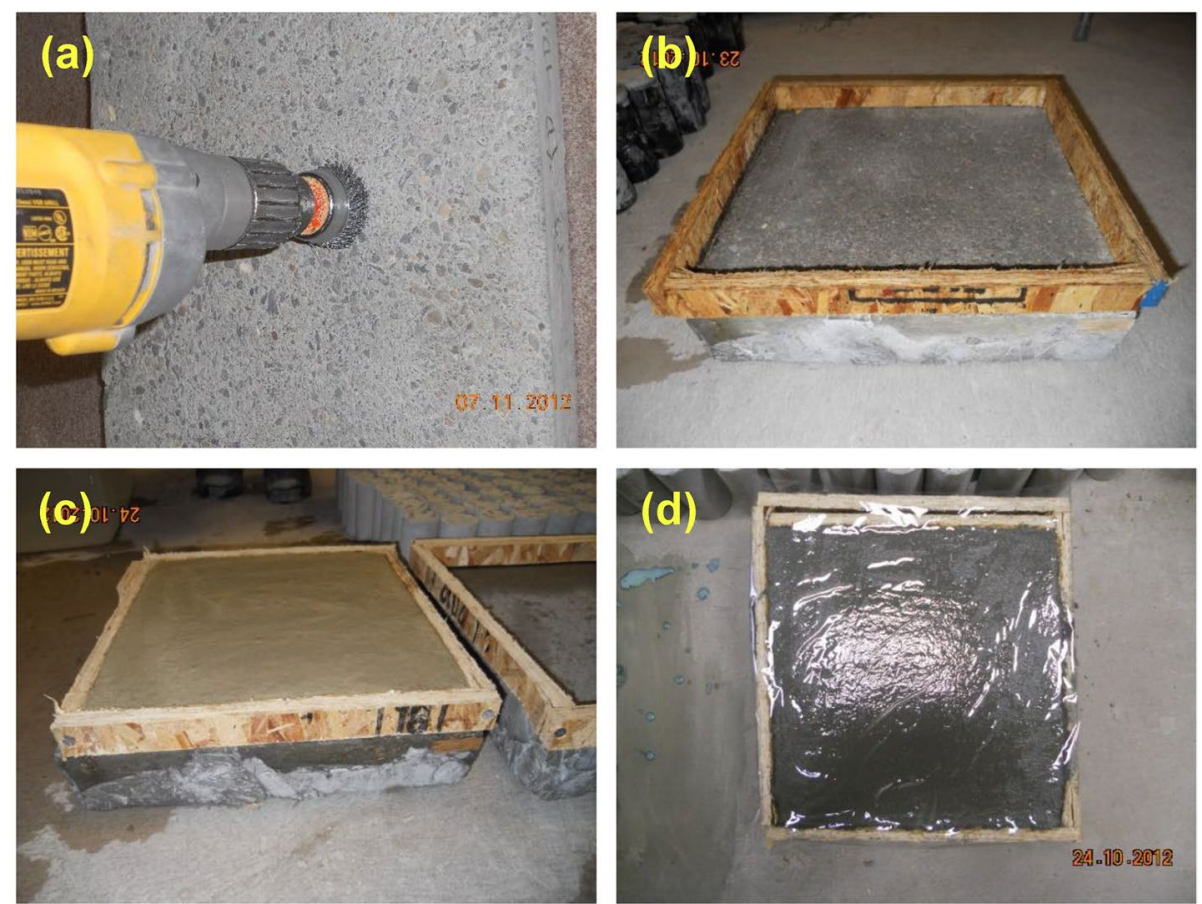

Fig. 1 Preparation of the cement-based overlays: a Brushing the surface of concrete slab; $\mathbf{b}$ Installing the framework and wetting the concrete slab; c Casting the cement-based overlays, and $\mathbf{d}$ Curing samples

Where $\mathrm{P}$ was the maximum load $(\mathrm{N})$, D was the diameter of cylinder samples $(\mathrm{mm})$, and $l$ was the height of cylinder samples $(\mathrm{mm})$.

\section{Abrasion resistance}

The abrasion resistance testing of concrete substrateoverlays composite specimens was conducted by using the Rotating-Cutter method following ASTM C944/ C944M-2009 entitled "Standard Test Method for Abrasion Resistance of Concrete or Mortar Surfaces by the Rotating-Cutter Method". To determine the abrasion resistance, cylindrical composite specimens in size of 2 in $\times 4$ in $(5 \mathrm{~cm} \times 10 \mathrm{~cm})$ drilled from composite slabs were used. Before performing tests, all specimens were kept in the open-air environment for at least $24 \mathrm{~h}$ to guarantee specimens were in an equivalent moisture condition at the beginning of abrasion testing. All specimens were abraded for three cycles of 2 min each (total of $6 \mathrm{~min}$ ) at 44-lb load, the change of height and mass was recorded, and the averaged value was determined as the testing results.

\section{Results and discussion Bond strength}

The change of bond strength after 10 cycles of $\mathrm{F} / \mathrm{T}$ and $\mathrm{W} / \mathrm{D}$ exposed to $15 \% \mathrm{NaCl}\left(\mathrm{MgCl}_{2}\right)$ solutions is illustrated in Fig. 2. It should be noted that the age of cementbased overlays (control, SFMO, LMO, and FMO) and substrate concrete slabs were $28 \mathrm{~d}$ and $56 \mathrm{~d}$ before starting the exposure cycles, respectively. The polymer overlays only needed $24 \mathrm{~h}$ of curing after casting; as such, the age of polymer overlays (T-48 and PPC-1121) and substrate concrete slabs were $1 \mathrm{~d}$ and $56 \mathrm{~d}$ before the weathering process, respectively. For T-48 polymer overlays, due to the special construction requirements, the top layer of aggregate made it very difficult to run the bond strength test, and it was thus not included in this discussion section. In order to process the FCE and AHP analysis in the later section, the bond strength of T-48 was assumed as the average value of all other overlays.

As shown in Fig. 2, the control sample was found to be comprehensively efficient in withstanding the weathering process, and SFMO was more adaptable in the $\mathrm{MgCl}_{2}$-laden environment. The fracture of composite samples, including the control, SFMO, FMO, and PPC1121, of the initial bonding strength tests occurred at the interfaces between the overlays and the concrete substrates, indicating that the bond strength was lower than the tensile strength of either overlay or concrete substrate. However, after chloride-laden weathering, the fractures of all cement-based overlay samples occurred in the concrete substrates rather than at the interfaces excepting the LMO in $\mathrm{NaCl}$-laden condition. This phenomenon indicated that the bond strength at interfaces between the cementitious overlay and the concrete 


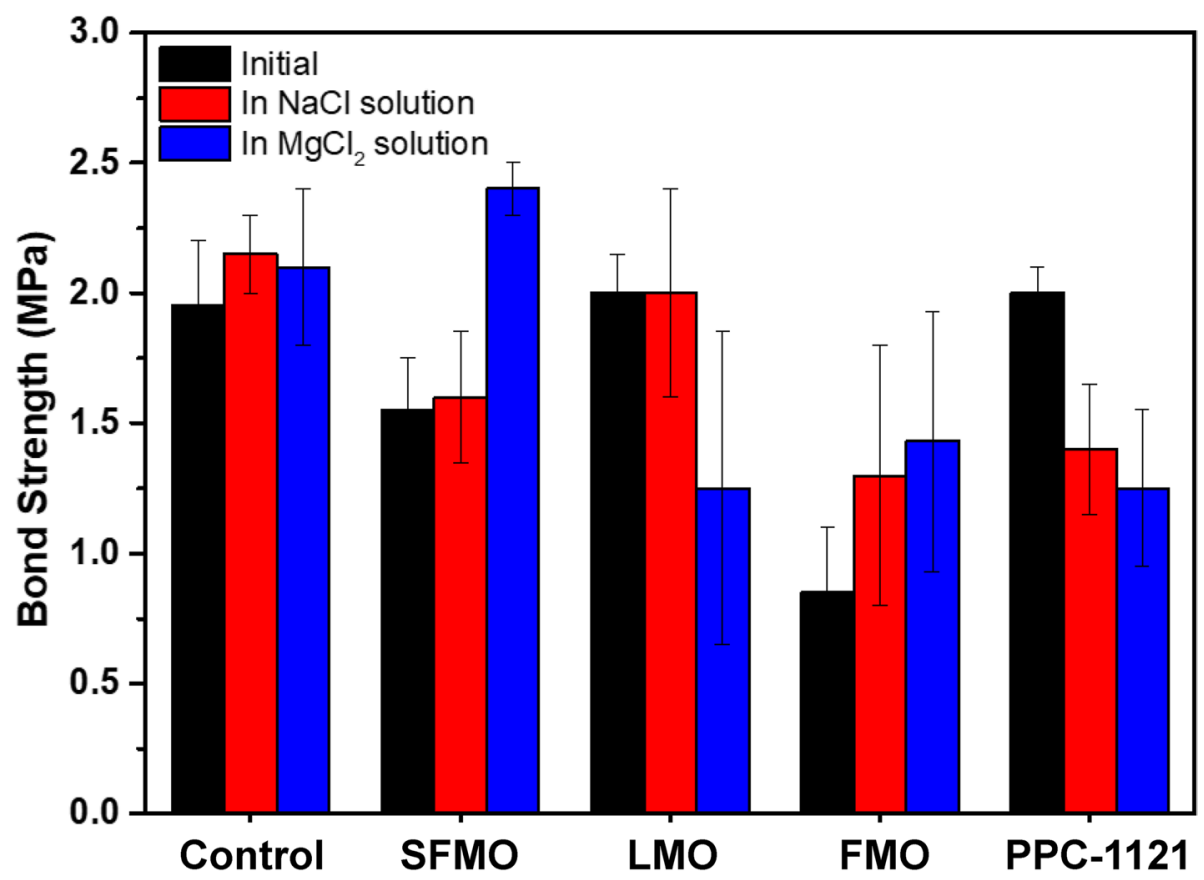

Fig. 2 Bond strength of various overlays

substrates was higher than the tensile strength of aged concrete substrates. One reason could be attributed to the growing bond strength at interface induced by the continuing hydration of cementitious materials [39], other reason could be explained by the degraded tensile strength of concrete substrate induced by the weathering process. However, the weight of these two mechanisms was hard to be evaluated quantitatively and more attention should be paid to this topic for further research. For the polymer PPC-1121 overlays, all the fractures occurred at the interfaces between the overlays and the substrates. Without chemical interaction, the bond strength at interface mainly depended on the physical adhesion, the weathering process damaged this adhesion and thus resulted in the bond strength of the aged PPC-1121 composite sample was lower than the original sample.

\section{Splitting tensile strength}

The results of splitting tensile (ST) strength of different concrete substrate-overlays composite cylinders after 10 cycles of $\mathrm{F} / \mathrm{T}-\mathrm{W} / \mathrm{D}$ in $15 \% \mathrm{NaCl}\left(\mathrm{MgCl}_{2}\right)$ solutions are presented in Fig. 3. As demonstrated in Fig. 3, the initial ST strength increased by the incorporation of LMO, FMO, T-48, and PPC-1121 samples while there was no significant change observed in the SFMO composite sample. After chloride-laden weathering, there was an obvious decreasing trend observed in LMO,
FMO, T-48, and PPC-1121 samples, excepting the controlled overlays sample in $\mathrm{NaCl}$ solution, and this difference needed to get more attention to be figured out in a more fundamental view. The total ST strength consists of the ST strength from both 1 in $(2.5 \mathrm{~cm})$ overlays and 3 in $(7.5 \mathrm{~cm})$ concrete substrate. FMO and T-48 composite cylinders featured obvious higher ST strength among others, and the main reason could be attributed to the higher ST strength of the overlays. For FMO overlays, the incorporated micro-fibers and nanoclay enhanced the ST strength extensively, and this result also agreed well with our previous work [33, 34]; for T-48 overlays, the enhanced ST strength could be due to the viscoelastic epoxy-fine aggregate composite overlays that absorbed more energy during the compressing process and thus resulted in a higher ST strength. After 10 cycles of $\mathrm{F} / \mathrm{T}$ and W/D in $15 \%$ $\mathrm{NaCl}\left(\mathrm{MgCl}_{2}\right)$ solutions, the difference of the residual ST strength of these specimens was not all statistically significant, the main reason for these decreases could be attributed to the severe degradation of the dominant 3 in $(7.5 \mathrm{~cm})$ concrete substrate induced by the coupled weathering effects, and the difference of ST strength between the 1 in $(2.5 \mathrm{~cm})$ overlays (either degraded cement-based or polymer overlays) might be insignificant because of the small size of overlays parts. It should be noted that this was only the preliminary result of the testing, more fundamental discussion was 


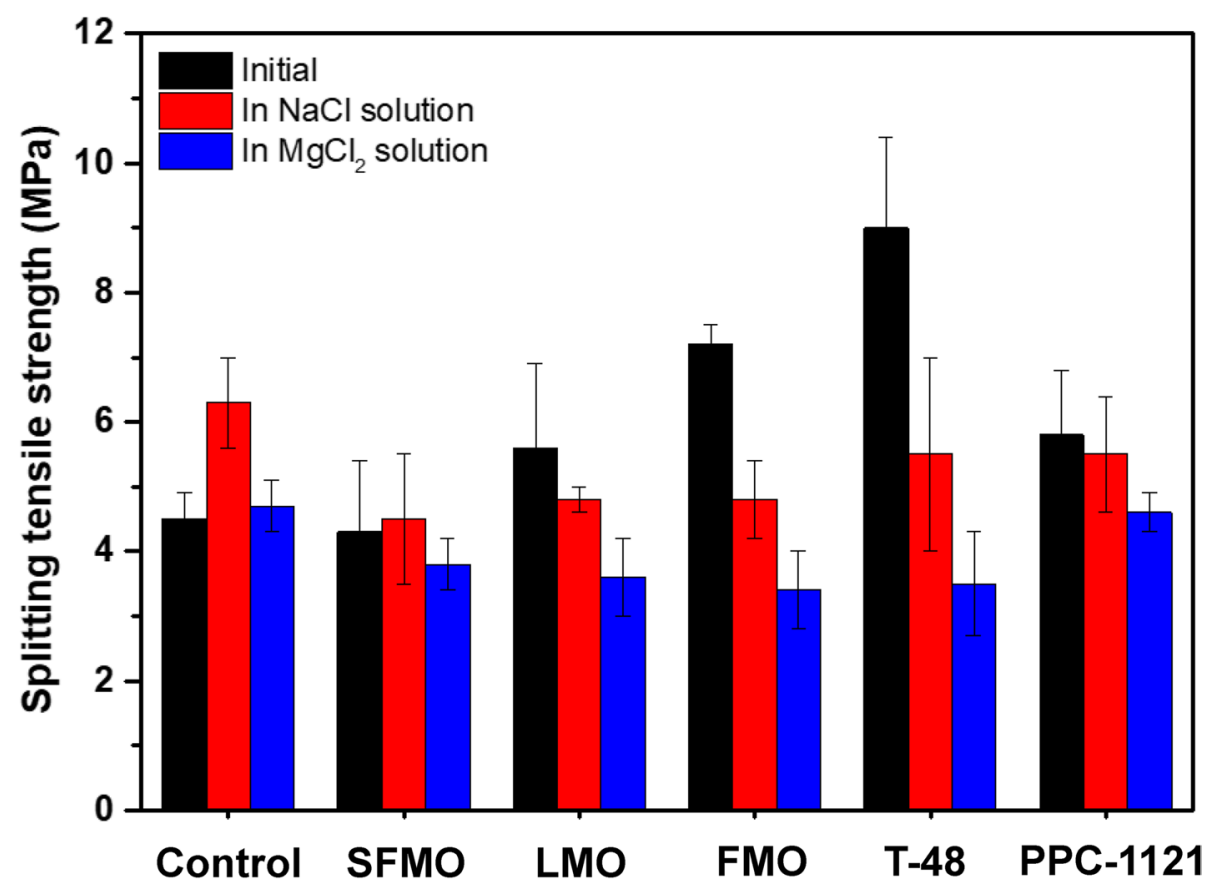

Fig. 3 Splitting tensile strength of concrete substrate incorporated with various overlays

needed to explain why different decrease ratio was observed in the same weathering conditions. There were two potential weakness planes in the cylinder composite samples: the interface between overlays and substrate and the usual splitting tensile plane. The interaction of these two crosswise planes made it difficult to analyze the results by conventional mechanics, and more efforts will be needed in the future to deal with this kind of problem, especially in these multiplelayered composite materials.

\section{Abrasion resistance}

The results of the abrasion resistance tests of the composite samples after 10 cycles of $F / T$ and $W / D$ in $15 \%$ $\mathrm{NaCl}\left(\mathrm{MgCl}_{2}\right)$ solutions are presented in Fig. 4. As shown in Fig. 4, the polymer overlays (T-48 and PPC1121) exhibited lower height change and mass loss than the cementitious overlays (control, FMO, SFMO, and LMO), indicating polymer overlays were more stable than cement-based overlays in the chloride-laden weathering process because the temperature and ions showed
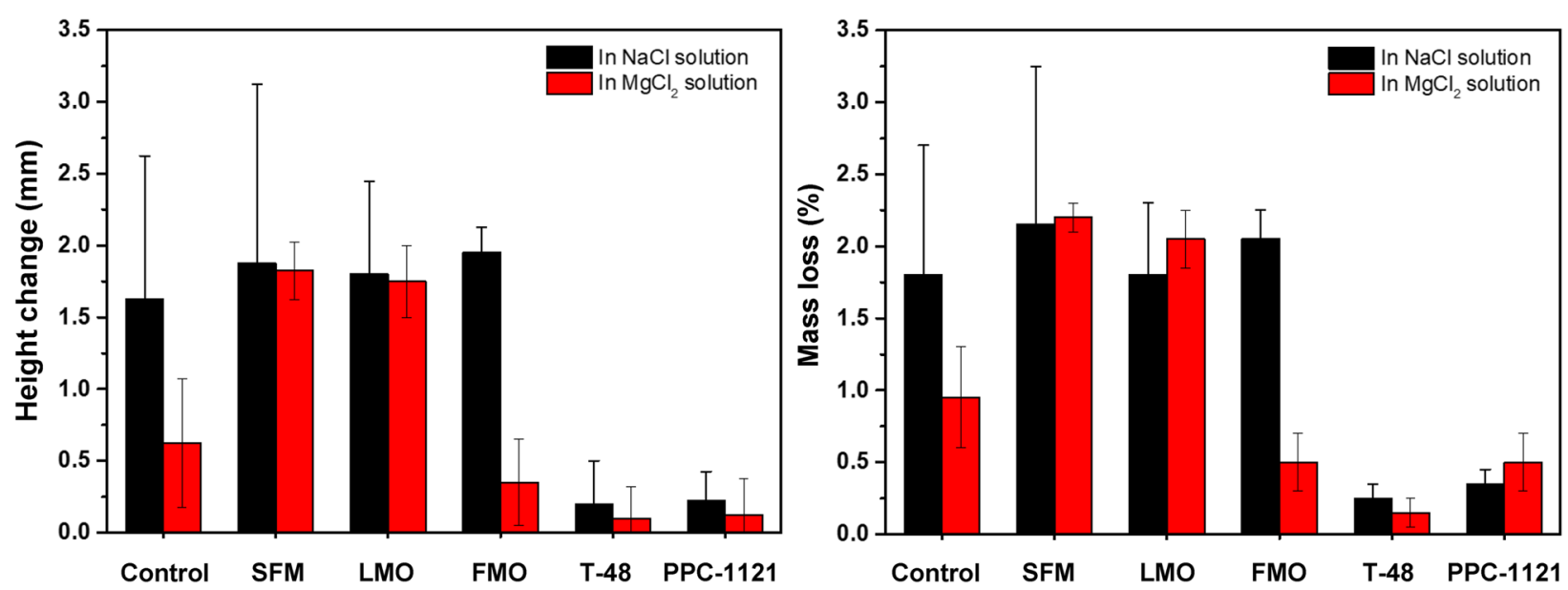

Fig. 4 Abrasion resistance of various overlays after F/T and W/D cycles exposed to deicer solutions: $\mathbf{a}$ height change; $\mathbf{b}$ mass loss 
almost no effects on the properties of hardened epoxy composites. In addition, the viscoelasticity of epoxy composites was more resistive to abrasion than rigid cement-based composites. The worse abrasion resistance of these cement-based overlays could be attributed to the presence of chloride-based deicers intensifying the F/T$\mathrm{W} / \mathrm{D}$ weathering, which had been proven in our previous research [36], many other researchers have also reported similar conclusions [22].

Figure 4 also reveals that the abrasion-induced height change and mass loss of the control and FMO overlays in $\mathrm{MgCl}_{2}$ solution are much lower than that in $\mathrm{NaCl}$ solution, while the difference of other cement-based overlays in these two scenarios was not statistically significant. Similar results were reported in our previous research that concrete samples in $10 \% \mathrm{MgCl}_{2}$ solution featured less mass loss and less scaling (a.k.a., less height change) than in $10 \% \mathrm{NaCl}$ solution [36], and our previous research also indicated the mass of samples in $\mathrm{MgCl}_{2}$ environment even increased which might be attributed to the cumulative generation of magnesium chloride salt inside the concrete. For SFM and LMO, the mass loss and height change in these two chloride scenarios were much similar indicating the incorporated silica fume and latex showed less influence to resist the erosion induced by both $\mathrm{MgCl}_{2}$ and $\mathrm{NaCl}$, and more fundamental research was also needed to figure out this mechanism in micro-/ nano-scale in future. The images of abraded samples were also listed in Fig. 5 to help understand the abrasion resistance illustrated in Fig. 4. In this study, the abrasion-induced height change strongly linearly correlated with the mass loss; as such, only the height change was considered as the index of abrasion resistance in the later FCE-AHP analysis.

\section{Fuzzy comprehensive evaluation method and analytical hierarchy process}

The FCE and AHP were applied to allow multi-criteria decision making, i.e., selection of the optimal overlays for the given service scenarios. In this study, the performance of various overlays was comprehensively evaluated by the bond strength (BS), splitting tensile strength (ST), and abrasion resistance (abraded height: $\mathrm{AH}$ ) in $\mathrm{NaCl}-$ and $\mathrm{MgCl}_{2}$-laden environments, respectively. These six parameters were defined as the evaluation factors $\left(U_{\mathrm{i}}\right.$, see Fig. 6a) and they were also assigned as the rows of the matrices $1 \sim 6$. All experimental results were standardized firstly before establishing the fuzzy mapping matrices (see Table 5) to remove the influence induced by the difference between various physical properties. For each factor, five appraisal grades were assigned (see Fig. 6b) based on the standardized data, they were $\mathrm{V}_{1}$ (very poor); $\mathrm{V}_{2}$ (poor); $\mathrm{V}_{3}$ (medium); $\mathrm{V}_{4}$ (good); and $\mathrm{V}_{5}$ (very good), respectively, and they were also assigned as the columns of the matrices $1 \sim 6$.

\section{Fuzzy mapping matrix and membership function}

A general membership function for all evaluation factors was established (see Fig. 7) and the mathematical form of membership function is presented in Eqs. (1) to (5). According to these five equations, the membership vectors of $U_{i}$ could be obtained by calculating the value of membership function based on the introduction of the standardized data. For example, the standardized value of $\mathrm{U}_{1}$ for control overlay was 1.00 ,

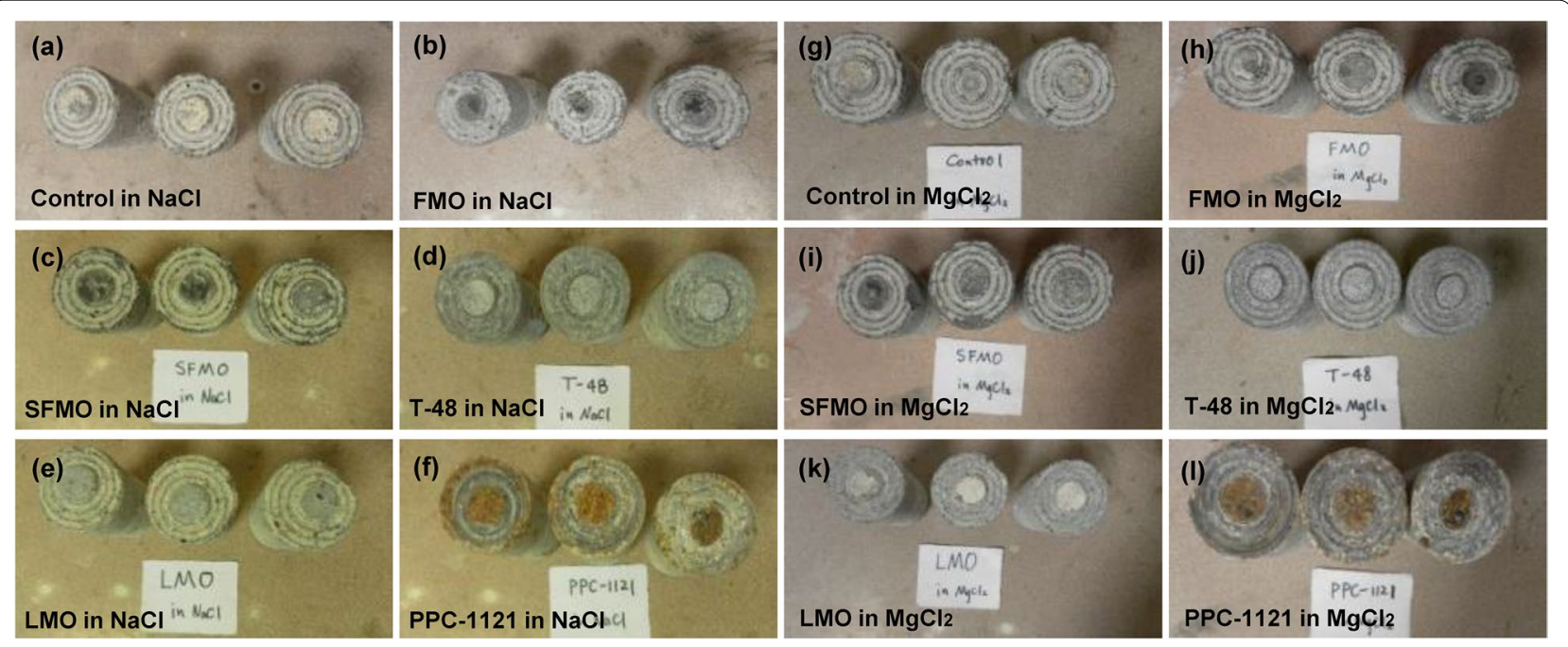

Fig. 5 The image of various concrete-substrate-overlay composites after erosion 


Fig. 6 a Evaluation factors set: $U_{i}$ and $\mathbf{b}$ appraisal grades set: $\mathrm{V}_{\mathrm{i}}$

Table 5 Original experimental data and corresponding standardized data

\begin{tabular}{lllllll}
\hline Factors & U1 & U2 & U3 & U4 & U5 & U6 \\
\hline Control & $2.15(1.00)$ & $2.1(0.88)$ & $6.3(1.00)$ & $4.7(1.00)$ & $1.625(0.12)$ & $0.625(0.16)$ \\
SFMO & $1.6(0.74)$ & $2.4(1.00)$ & $4.5(0.71)$ & $3.8(0.81)$ & $1.875(0.11)$ & $1.825(0.05)$ \\
LMO & $2.0(0.93)$ & $1.25(0.52)$ & $4.8(0.76)$ & $3.6(0.77)$ & $1.8(0.11)$ & $1.75(0.06)$ \\
FMO & $1.3(0.60)$ & $1.43(0.60)$ & $4.8(0.76)$ & $3.4(0.72)$ & $1.95(0.10)$ & $0.35(0.29)$ \\
T48 & $1.69(0.79)$ & $1.686(0.70)$ & $5.5(0.87)$ & $3.5(0.74)$ & $0.2(1.00)$ & $0.1(1.00)$ \\
PPC-1121 & $1.4(0.65)$ & $1.25(0.52)$ & $5.5(0.87)$ & $4.6(0.98)$ & $0.225(0.89)$ & $0.125(0.80)$ \\
\hline
\end{tabular}

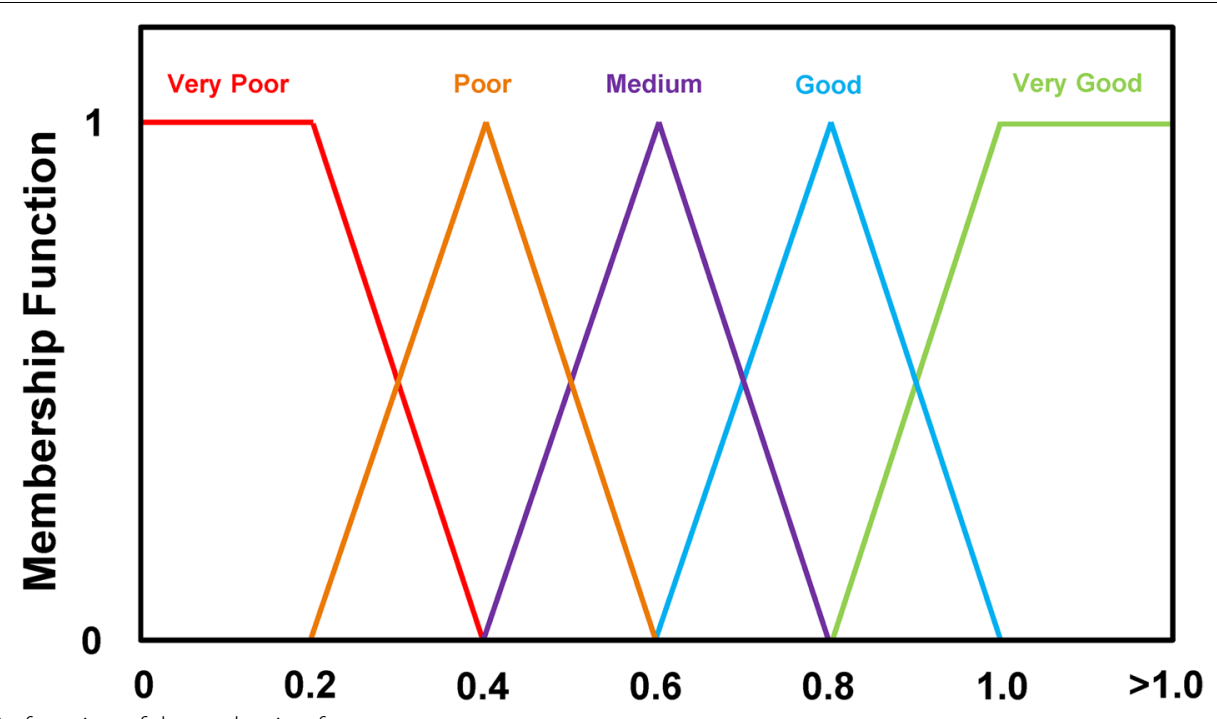

Fig. 7 Membership function of the evaluation factors 
the $\quad \widetilde{\mathrm{A}}_{11}(1)=0 ; \widetilde{\mathrm{A}}_{12}(1)=0 ; \quad \widetilde{\mathrm{A}}_{13}(1)=0 ; \widetilde{\mathrm{A}}_{14}(1)=0$; $A_{15}(1)=1$. Therefore, the membership vector of $U_{1}$ for control overlay was written as $(0,0,0,0,1)$.

$$
\begin{aligned}
& \tilde{A}_{i 1}(x)= \begin{cases}1 & \mathrm{x}<0.2 \\
(0.4-\mathrm{x}) /(0.4-0.2) & 0.2<=\mathrm{x}<0.4 \\
0 & \text { others }\end{cases} \\
& \tilde{A}_{i 2}(x)= \begin{cases}(0.6-\mathrm{x}) /(0.6-0.4) & 0.4<\mathrm{x}<0.6 \\
(\mathrm{x}-0.2) /(0.4-0.2) & 0.2<=\mathrm{x}<0.4 \\
0 & \text { others }\end{cases} \\
& \tilde{A}_{i 3}(x)= \begin{cases}(0.8-\mathrm{x}) /(0.8-0.6) & 0.6<\mathrm{x}<0.8 \\
(\mathrm{x}-0.4) /(0.6-0.4) & 0.4<=\mathrm{x}<0.6 \\
0 & \text { others }\end{cases} \\
& \tilde{A}_{i 4}(x)= \begin{cases}(1-\mathrm{x}) /(1-0.8) & 0.8<\mathrm{x}<1 \\
(\mathrm{x}-0.6) /(0.8-0.6) & 0.6<=\mathrm{x}<0.8 \\
0 & \text { others }\end{cases} \\
& \tilde{A}_{i 5}(x)= \begin{cases}1 & \mathrm{x}>1 \\
(\mathrm{x}-0.8) /(1-0.8) & 0.8<=\mathrm{x}<0.1 \\
0 & \text { others }\end{cases}
\end{aligned}
$$

\begin{tabular}{|c|c|c|c|c|}
\hline $\mathrm{R}_{\mathrm{T} 48}=[$ & $\begin{array}{llc}0 & 0 & 0.0 \\
0 & 0 & 0 . \\
0 & 0 & 0 \\
0 & 0 & 0 . \\
0 & 0 & 0 \\
0 & 0 & 0\end{array}$ & $\begin{array}{cc}0.95 & 0 \\
0.5 & 0 \\
0.65 & 0.35 \\
0.7 & 0 \\
0 & 1 \\
0 & 1\end{array}$ & & Matrix (5) \\
\hline $\mathrm{R}_{\mathrm{PCC1121}}=$ & $=\left[\begin{array}{ll}0 & 0 \\
0 & 0 . \\
0 & 0 \\
0 & 0 \\
0 & 0 \\
0 & 0\end{array}\right.$ & $\begin{array}{cc}0.75 & 0.25 \\
0.6 & 0 \\
0 & 0.65 \\
0 & 0.1 \\
0 & 0.55 \\
0 & 1\end{array}$ & $\left.\begin{array}{c}0 \\
0 \\
0.35 \\
0.9 \\
0.45 \\
0\end{array}\right]$ & Matrix (6) \\
\hline
\end{tabular}

By repeating this process, the fuzzy mapping matrices of all overlays were developed and provided as follows:

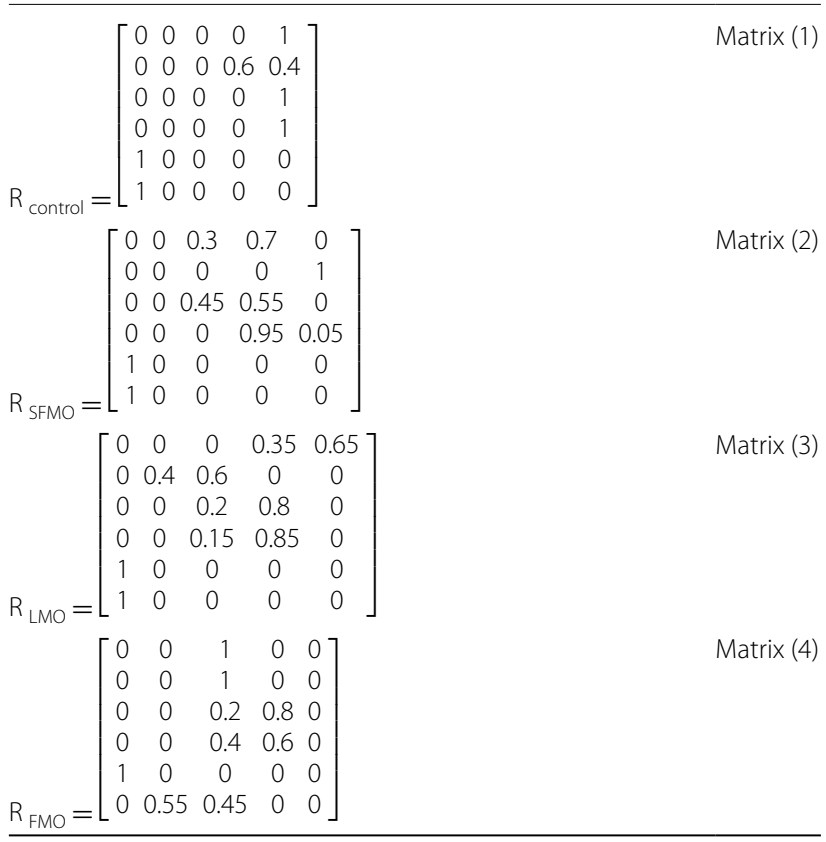

The matrices $1 \sim 6$ illustrate the potential grade of certain performance of each overlay product. The value of 1 in the column indicates that the corresponding performance (Row: a.k.a. evaluation factor: $U$ ) of this overlay is exactly located at the assigned level (Column: a.k.a. appraisal grade: V). For example, in matrix 1, the value of 1 located in the 1 st row and 5 th column, indicating that the bond strength in NaCl-laden environments $\left(\mathrm{U}_{1}\right)$ of control overlay samples was very good $\left(V_{5}\right)$. The neighboring value in the columns, with a sum of 1 , indicates that the corresponding performance of this overlay is fuzzily located between the two neighboring assigned levels. For example, in matrix 1, the value of $0.6(0.4)$ located in the 2nd row and 4th (5th) column, indicating that the bond strength in $\mathrm{MgCl}_{2}$-laden environments $\left(\mathrm{U}_{2}\right)$ of control overlay samples was between good level (V4) with $60 \%$ weight and very good level $\left(\mathrm{V}_{5}\right)$ with $40 \%$ weight. All these fuzzy mapping matrices were the prerequisite for calculating the comprehensive evaluation vectors in the comprehensive evaluation vectors subsection.

\section{Weight vector derived by AHP}

The pairwise comparisons (see Table 6) were summarized based on the "relative importance" of different factors [12], and the pairwise comparison matrices of these evaluation factors in targeted scenarios were derived by AHP. The results are provided in Tables 7, 8 and 9.

This study examines three different winter road maintenance operations scenarios and assigns different judgment matrices to these scenarios. In WA state, both $\mathrm{NaCl}$-based and $\mathrm{MgCl}_{2}$-based deicers are applied while studded tires are also allowed during the winter season; as such, all the overlay performance factors were considered equally important (see Table 7). In OR state, the application of $\mathrm{MgCl}_{2}$-based deicers is dominant and very little (if any) $\mathrm{NaCl}$-based deicer is used, whereas the application of $\mathrm{NaCl}$-based deicers is dominant in B.C. (Canada); studded tires are also allowed in these two regions. Therefore, a judgment matrix and its transpose were assigned to OR and B.C. (see Tables 8 and 9), 
Table 6 Summary of pairwise comparison values

\begin{tabular}{|c|c|c|}
\hline $\begin{array}{l}\text { Intensity of } \\
\text { importance }\end{array}$ & Definition & Explanation \\
\hline 1 & Equal importance & Two activities contributed equally to the objective \\
\hline 2 & Weak importance & Experience and judgment slightly favored one activity over another \\
\hline 5 & Absolute importance & $\begin{array}{l}\text { The evidence that favored one activity over another was of the } \\
\text { highest possible order of affirmation }\end{array}$ \\
\hline $\begin{array}{l}\text { Reciprocals } \\
\text { of previous } \\
\text { nonzero }\end{array}$ & \multicolumn{2}{|c|}{$\begin{array}{l}\text { If activity i has one of the previous nonzero numbers assigned to it when compared with activity } j \text {, then } j \text { has the reciprocal value when } \\
\text { compared with } i\end{array}$} \\
\hline
\end{tabular}

Table 7 Weight judgment matrix used for WA

\begin{tabular}{lllllll}
\hline & BS-Na & BS-Mg & ST Na & ST Mg & AH Na & AH Mg \\
\hline BS-Na & 1 & 1 & 1 & 1 & 1 & 1 \\
BS-Mg & 1 & 1 & 1 & 1 & 1 & 1 \\
ST-Na & 1 & 1 & 1 & 1 & 1 & 1 \\
ST-Mg & 1 & 1 & 1 & 1 & 1 & 1 \\
EH-Na & 1 & 1 & 1 & 1 & 1 \\
EH-Mg & 1 & 1 & & & 1 & 1 \\
\hline
\end{tabular}

Table 8 Weight judgment matrix used for OR

\begin{tabular}{|c|c|c|c|c|c|c|}
\hline & BS-Na & BS-Mg & ST Na & ST Mg & $\mathrm{AH} \mathrm{Na}$ & $\mathrm{AH} \mathrm{Mg}$ \\
\hline BS-Na & 1 & 0.2 & 1 & 0.2 & 1 & 0.2 \\
\hline BS-Mg & 5 & 1 & 5 & 1 & 5 & 1 \\
\hline ST-Na & 1 & 0.2 & 1 & 0.2 & 1 & 0.2 \\
\hline ST-Mg & 5 & 1 & 5 & 1 & 5 & 1 \\
\hline $\mathrm{AH}-\mathrm{Na}$ & 1 & 0.2 & 1 & 0.2 & 1 & 0.2 \\
\hline $\mathrm{AH}-\mathrm{Mg}$ & 5 & 1 & 5 & 1 & 5 & 1 \\
\hline
\end{tabular}

Table 9 Weight judgment matrix used for B.C

\begin{tabular}{|c|c|c|c|c|c|c|}
\hline & BS-Na & BS-Mg & ST Na & ST Mg & $\mathrm{AH} \mathrm{Na}$ & $\mathrm{AH} \mathrm{Mg}$ \\
\hline BS-Na & 1 & 5 & 1 & 5 & 1 & 5 \\
\hline BS-Mg & 0.2 & 1 & 0.2 & 1 & 0.2 & 1 \\
\hline ST-Na & 1 & 5 & 1 & 5 & 1 & 5 \\
\hline ST-Mg & 0.2 & 1 & 0.2 & 1 & 0.2 & 1 \\
\hline $\mathrm{AH}-\mathrm{Na}$ & 1 & 5 & 1 & 5 & 1 & 5 \\
\hline $\mathrm{AH}-\mathrm{Mg}$ & 0.2 & 1 & 0.2 & 1 & 0.2 & 1 \\
\hline
\end{tabular}


Table 10 Comprehensive evaluation vector and final grades of overlays in WA

\begin{tabular}{lll}
\hline Overlays & Comprehensive evaluation vector & Final grades \\
\hline Control & $(0.333,0,0,0.1,0.567)$ & 61.36 \\
SFMO & $(0.333,0,0.125,0.367,0.175)$ & 51.02 \\
LMO & $(0.333,0.067,0.158,0.333,0.275)$ & 61.3 \\
FMO & $(0.167,0.092,0.508,0.233,0.167)$ & 61.17 \\
T-48 & $(0,0,0.142,0.467,0.558)$ & 90.01 \\
PPC-1121 & $(0,0.067,0.225,0.425,0.45)$ & 83.51 \\
\hline
\end{tabular}

Table 11 Comprehensive evaluation vector and final grades of overlays in OR

\begin{tabular}{lll}
\hline Overlays & Comprehensive evaluation vector & Final grades \\
\hline Control & $(0.333,0,0,0.167,0.5)$ & 60.02 \\
SFMO & $(0.333,0,0.042,0.333,0.292)$ & 55.02 \\
LMO & $(0.333,0.111,0.219,0.3,0.314)$ & 66.87 \\
FMO & $(0.056,0.153,0.251,0.211,0.278)$ & 57.49 \\
T-48 & $(0,0,0.225,0.422,0.631)$ & 97.58 \\
PPC-1121 & $(0,0.11,0.208,0.386,0.572)$ & 92.23 \\
\hline
\end{tabular}

Table 12 Comprehensive evaluation vector and final grades of overlays in B.C

\begin{tabular}{lll}
\hline Overlays & Comprehensive evaluation vector & Final grades \\
\hline Control & $(0.333,0,0,0.033,0.633)$ & 62.61 \\
SFMO & $(0.333,0,0.208,0.4,0.058)$ & 46.95 \\
LMO & $(0.333,0.022,0.097,0.367,0.236)$ & 55.77 \\
FMO & $(0.278,0.031,0.436,0.256,0.055)$ & 48.38 \\
T-48 & $(0,0,0.058,0.511,0.486)$ & 82.41 \\
PPC-1121 & $(0,0.022,0.242,0.464,0.328)$ & 74.76 \\
\hline
\end{tabular}

respectively. After determining the judgment matrices, the maximum eigenvalue-related eigenvectors for these three matrices were calculated (see below) for developing the comprehensive evaluation vectors.

$W_{W A}=(0.1667,0.1667,0.1667,0.1667,0.1667,0.1667)$

Vector (1)

$W_{O R}=(0.0555,0.2778,0.0555,0.2778,0.0555,02778)$

Vector (2)

$W_{B C}=(0.2778,0.0555,0.2778,0.0555,0.2778,0.0555)$

Vector (3)

\section{Comprehensive evaluation vectors}

The comprehensive evaluation vectors were obtained via the multiplication of the standardized eigenvectors by the fuzzy mapping matrices, and the results are presented in Tables 10, 11 and 12. By assigning the specific score for each grade, $10,30,50,70$, and 90 points corresponding to very poor grade, poor grade, medium grade, good grade, and very good grade, respectively, one can obtain the final scores of each overlay via the multiplication of the comprehensive evaluation vector by the score vector, and the results are presented in Tables 10, 11 and 12 as well. For example, the comprehensive evaluation vector for the control overlay in WA was $(0.333,0,0,0.1,0.567)$, its final grade was $(0.333,0,0,0.1,0.567)^{*}(10,30,50,70,90)^{\mathrm{T}}=61.36$. As known from the following tables, T-48 overlay exhibited more promising performance than others and it could be applied in all these three regions, PCC-1121 overlay took second place, while the relative rank of the remaining overlays varied in different scenarios.

\section{Conclusions}

When the concrete slabs have deteriorated to a relatively severe degree, overlays should be considered as a preservation or rehabilitation option prior to the option of reconstruction. This laboratory study measured the bond strength, splitting tensile strength, abrasion-induced height change and mass loss of bridge concrete slabs, which were first treated with different types of overlays and then exposed to 10 cycles of rapid F/T and W/D in $15 \% \mathrm{NaCl}$ or $\mathrm{MgCl}_{2}$ solution.

Compared with cement-based overlays, polymer overlays (T-48 and PPC-1121) showed less abrasion loss and less "scaling" mass loss, and they should be considered as candidates in regions that require high abrasion resistance. In addition, these two polymer overlays are more hydrophobic than cement-based overlays by design, and their reduced water absorption will likely benefit the long-term durability performance. Future study, however, should further evaluate the resistance of polymer overlays to ultraviolet (UV) aging, which is a valid consideration for overlays in regions with high solar radiation. When serving as a riding surface, the overlays should also be evaluated for their friction coefficient (i.e., safety performance).

Different from $\mathrm{NaCl}, \mathrm{MgCl}_{2}$ resulted in less abrasion loss and less "scaling" mass loss than the control and LMO overlays but caused a more significant decrease in their splitting tensile strength. This is consistent with our prior finding that $\mathrm{MgCl}_{2}$ deicer attack stems from internal damage of the concrete and is manifested as a substantial reduction in splitting tensile strength but no visible surface distress [4, 36]. Future work should be focused on mechanistic studies so as to link the protective performance of overlays to their physicochemical characteristics at multiple length scales. It is also important to investigate the physical and chemical interactions 
of overlay with the underlying concrete slab as well as the degradation of their interface. Such fundamental knowledge will guide the development of more infrastructure-friendly deicer products and more deicer-resistant concrete mixtures for overlay applications. Research is also needed in connecting the accelerated laboratory test protocols with actual field exposure conditions and performances of overlays, as well as in life cycle assessment of cost and environmental footprint of their use in the specific service environment.

This study demonstrated a multi-criteria decision-making method, FCE combined with AHP, for the selection of optimal overlays in three different service scenarios (e.g., states of Washington and Oregon [USA] and British Columbia [Canada]). The analysis results indicate that one epoxy overlay (T48) exhibited the comprehensively best performance and could be a promising candidate in all three given scenarios, another polymer overlay (PPC-1121) took second place, while the adaptability of the three cement-based overlays varied in different environments.

\begin{abstract}
Abbreviations
F/T: Freeze/thaw; W/D: Wet/dry; PCC: Portland cement concrete; FCE: Fuzzy comprehensive evaluation; AHP: Analytic hierarchy process; B.C.: British Columbia; TEA: Triethanolamine; LMO: Latex modified mortar overlay; SFMO: Silica Fume modified mortar overlay; FMO: Microfiber-Nanoclay reinforced mortar overlay; ASTM: American Society for Testing and Materials; ST: Splitting tensile strength; BS: Bond strength; $\mathrm{AH}$ : Abraded height; UV: Ultraviolet.
\end{abstract}

\section{Acknowledgments}

Most of the laboratory work was completed at the Western Transportation Institute where Drs. Dang, Xie and Shi worked. The authors are indebted to the ODOT Research Coordinator Steven Soltesz and the AUTC project manager Billy Connor. The authors thank members of the technical panel (Michael Coffey at Alaska DOT\&PF; Tim Rogers at FHWA; and Rick Poecker, Ray Bottenberg, and James Garrard at ODOT) for their guidance. The authors thank Transpo Industries, Inc. and Kwik Bond Polymers, Inc. for supplying the overlay products. The authors also extend their sincere gratitude to many students at WTI (Stephen Mery, Amanda Olsen, Andrew Benson, and Peng Lei) for their assistance in some tasks. In addition, the authors acknowledge Lucas Thoms for the marked WA, OR, and B.C. maps online. The conclusions in this study are based on the testing results under the given conditions, which may differ from field conditions. The brand names of products were provided for readers' convenience only and do not imply any endorsement (or otherwise)

\section{Authors' contributions}

Z. Li: Writing - reviewing and editing, Data analysis; Y. Dang: Supervision, Methodology, Writing - original draft preparation; Z. Tang: Data processing; N. Xie: Investigation, Writing - original draft preparation; S. Lu: Supervision, Data analysis; X. Shi: Funding, Conceptualization, Methodology, Data analysis, Writing - reviewing and editing. All authors read and approved the final manuscript.

\section{Funding}

The authors acknowledge the financial support provided by the Oregon Department of Transportation (ODOT) as well as the USDOT Research \& Innovative Technology Administration (RITA) through Alaska University Transportation Center and Western Transportation Institute. Part of this work was financially supported by the China Postdoctoral Science Foundation (No. 2016 M592723).

\section{Availability of data and materials}

Data will be made available upon reasonable request. The processed data reported in this paper and the FTIR spectra data of the two polymers used for the polymeric overlays are available at: https://research.wsulibs.wsu.edu/ xmlui/handle/2376/19335.

\section{Declarations}

\section{Competing interests}

The authors declare no competing interest.

\section{Author details}

${ }^{1}$ Department of Civil \& Environmental Engineering, Washington State University, P. O. Box 642910, Pullman, WA 99164-2910, USA. ${ }^{2}$ Yunnan Key Laboratory of Building Structure and New Materials, Yunnan Institute of Building Research, Kunming 650223, China. 'Key Lab of Structure Dynamic Behavior and Control, Ministry of Education, Harbin 150090, Heilongjiang, China. ${ }^{4}$ School of Civil Engineering, Harbin Institute of Technology, Harbin 150090, Heilongjiang, China. ${ }^{5}$ Shandong Provincial Key Laboratory of Preparation and Measurement of Building Materials, University of Jinan, Jinan 250022, Shandong, China.

Received: 30 September 2021 Accepted: 11 November 2021

Published online: 22 December 2021

\section{References}

1. Abo Sabah SH, Hassan MH, Muhamad Bunnori N, Megat Johari MA (2019) Bond strength of the interface between normal concrete substrate and GUSMRC repair material overlay. Constr Build Mater 206:261-271. https:// doi.org/10.1016/j.conbuildmat.2019.04.270

2. Chanvillard G, Aitcin PC, Lupien C (1989) Field evaluation of steel-fiber reinforced concrete overlay with various bonding mechanisms. Transp Res Rec 1226:48-56

3. Corsi SR, De Cicco LA, Lutz MA, Hirsch RM (2015) River chloride trends in snow-affected urban watersheds: increasing concentrations outpace urban growth rate and are common among all seasons. Sci Total Environ 508:488-497. https://doi.org/10.1016/j.scitotenv.2014.12.012

4. Dang Y, Shi X, Xie N, McVey E, Kessel A (2016) Accelerated laboratory test suggests the importance of film integrity of sealers on the protection of concrete from deicer scaling. J Mater Civ Eng 28(9):04016065

5. Fay L, Shi X (2011) Laboratory investigation of performance and impacts of snow and ice control chemicals for winter road service. J Cold Reg Eng 25(3):89-114. https://doi.org/10.1061/(asce)cr.1943-5495.0000025

6. Federal Highway Administration (2005). "How Do Weather Events Impact Roads?". https://ops.fhwa.dot.gov/weather/q1_roadimpact.htm

7. Freeseman K, Wang K, Tan Y (2020) Bond strength and chloride resistance of epoxy and concrete overlays on bridge decks. Int J Pavement Eng 1-6. https://doi.org/10.1080/10298436.2020.1778693

8. Haber ZB, Munoz JF, Graybeal BA (2017) Field testing of an ultra-high performance concrete overlay (No. FHWA-HRT-17-096). United States, Federal Highway Administration, Office of Infrastructure Research and Development. McLean, VA, USA

9. Jain J, Olek J, Janusz A, Jozwiak-Niedzwiedzka D (2012) Effects of deicing salt solutions on physical properties of pavement concretes. Transport Res Rec 2290:69-75. https://doi.org/10.3141/2290-09

10. Jang JW, Iwasaki I, Gillis HJ, Weiblen PW (1995) Effect of corrosioninhibitor-added deicing salts and salt substitutes on reinforcing steels. 1. influence of concentration. Adv Cem Based Mater 2(4):145-151. https:// doi.org/10.1016/1065-7355(94)00048-i

11. Janssen DJ (1985) The effect of asphalt concrete overlays on the progression of durability cracking in Portland cement concrete. (D-Cracking, Frost, Freeze-Thaw, Autogenous Healing) (Doctoral dissertation, University of Illinois at Urbana-Champaign). Champaign, IL, USA.

12. Jungwirth S, Shi X (2017) Laboratory investigation of naturally sourced liquid deicers and subsequent decision support. J Cold Reg Eng 31(3). https://doi.org/10.1061/(asce)cr.1943-5495.0000132

13. Kuhlmann LA (1985) Latex modified concrete for the repair and rehabilitation of bridges. Int J Cem Compos Light Concr 7(4):241-247 
14. Liu X, Ni C, Zhang L, Sheng K, Hong B (2019) Durability assessment of lightweight cellular concrete in subgrade by the method of analytic hierarchy process combined with fuzzy comprehensive evaluation. Math Probl Eng 2019. https://doi.org/10.1155/2019/4915870

15. Pigeon M, Pleau R (1995) Durability of concrete in cold climates. E and FN Spon, New York

16. Qiao C, Hosseinzadeh N, Suraneni P, Wei S, Rothstein D (2021) Petrographically quantifying the damage to field and lab-cast mortars subject to freeze-thaw cycles and deicer application. J Infrastruct Preserv Resil 2(1):1-12

17. Reiterman P, Keppert M (2020) Effect of various De-Icers containing chloride ions on scaling resistance and chloride penetration depth of highway concrete. Roads Bridges-Drogi I Mosty 19:51-64. https://doi.org/ 10.7409/rabdim.020.003

18. Russell HG (2004) Concrete bridge deck performance. NCHRP report 333. Transportation Research Board, Washington, D.C.

19. Shi X, Liu Y, Mooney M, Berry M, Hubbard B, Nguyen TA (2010a) Laboratory investigation and neural networks modeling of deicer ingress into Portland cement concrete and its corrosion implications. Corros Rev 28(3-4):105-153. https://doi.org/10.1515/corrrev.2010.28.3-4.105

20. Shi X, Fay L, Peterson MM, Yang Z (2010b) Freeze-thaw damage and chemical change of a Portland cement concrete in the presence of diluted deicers. Mater Struct 43(7):933-946. https://doi.org/10.1617/ s11527-009-9557-0

21. Shi X, Xie N, Dang Y, Muthumani A, Huang J, Hagel A et al (2014) Understanding and mitigating effects of chloride deicer exposure on concrete (No. FHWA-OR-RD-15-08). Oregon. Dept. of Transportation, Salem

22. Sumsion ES, Guthrie WS (2013) Physical and chemical effects of deicers on concrete pavement: literature review (No. UT-13.09)

23. Sun W, Mu R, Lua X, Miao CW (2002) Effect of chloride salt, freeze-thaw cycling and externally applied load on the performance of the concrete. Cem Concr Res 32(12):1859-1864. https://doi.org/10.1016/s00088846(02)00769-x

24. Suraneni P, Azad VJ, Isgor OB, Weiss WJ (2016) Deicing salts and durability of concrete pavements and joints. Concr Int 38(4):48-54

25. Sutter L, Dam T, Peterson K, Johnston D (2006a) Long-term effects of magnesium chloride and other concentrated salt solutions on pavement and structural Portland cement concrete: phase I results. Transp Res Rec 1979:60-68. https://doi.org/10.1177/0361198106197900109

26. Sutter L, Peterson K, Touton S, Van Dam T, Johnston D (2006b) Petrographic evidence of calcium oxychloride formation in mortars exposed to magnesium chloride solution. Cem Concr Res 36(8):1533-1541. https://doi.org/10.1016/j.cemconres.2006.05.022

27. Sutter L, Peterson K, Julio-Betancourt G, Hooton D, Vam Dam T, Smith K (2008) The deleterious chemical effects of concentrated deicing solutions on Portland cement concrete. South Dakota Department of Transportation, Pierre Final report SD2002-01-F

28. Truschke C, Peterson K, Van Dam T, Peshkin D, DeDene C, DeDios R (2011) Investigation of Portland cement concrete exposed to automated deicing solutions on Colorado's bridge decks. Transp Res Rec 22(20):1-11. https://doi.org/10.3141/2220-01

29. Verian K, Behnood A (2018) Effects of deicers on the performance of concrete pavements containing air-cooled blast furnace slag and supplementary cementitious materials. Cem Concr Compos 90:27-41. https:// doi.org/10.1016/j.cemconcomp.2018.03.009

30. Wang JQ, Dai QL, Guo SC, Si SZ (2019) Mechanical and durability performance evaluation of crumb rubber-modified epoxy polymer concrete overlays. Constr Build Mater 203:469-480. https://doi.org/10.1016/j. conbuildmat.2019.01.085

31. Wang Z, Zeng Q, Wang L, Yao Y, Li K (2014) Corrosion of rebar in concrete under cyclic freeze-thaw and chloride salt action. Constr Build Mater 53:40-47. https://doi.org/10.1016/j.conbuildmat.2013.11.063

32. Weyers RE, Fitch MG, Larsen EP, Al-Qadi IL, Chamberlin WP, Hoffman PC (1994) Concrete bridge protection and rehabilitation: chemical and physical techniques. Service life estimates. Report no. SHRP-S-668. Strategic Highway Research Program, Washington, D.C.

33. Wang Y, Zhang S, Li G, Shi X (2019a) Effects of alkali-treated recycled carbon fiber on the strength and free drying shrinkage of cementitious mortar. J Clean Prod 228:1187-1195. https://doi.org/10.1016/j.jclepro. 2019.04.295
34. Wang Y, Zhang S, Luo D, Shi X (2019b) Effect of chemically modified recycled carbon fiber composite on the mechanical properties of cementitious mortar. Compos Part B 173:106853. https://doi.org/10.1016/j.compo sitesb.2019.05.064

35. Xie N, Shi X, Zhang Y (2017) Impacts of potassium acetate and sodiumchloride deicers on concrete. J Mater Civil Eng 29(3). https://doi.org/10. 1061/(asce)mt.1943-5533.0001754

36. Xie N, Dang Y, Shi X (2019) New insights into how $\mathrm{MgCl}_{2}$ deteriorates Portland cement concrete. Cem Concr Res 120:244-255. https://doi.org/ 10.1016/j.cemconres.2019.03.026

37. Xu G, Shi X (2018) Impact of chemical deicers on roadway infrastructure: risks and best management practices. In: Sustainable winter road operations, pp 211-240

38. Yu H, Chen Y, Wu Q, Zhang L, Zhang Z, Zhang J, Miljković M, Oeser M (2020) Decision support for selecting optimal method of recycling waste tire rubber into wax-based warm mix asphalt based on fuzzy comprehensive evaluation. J Clean Prod 265:121781. https://doi.org/10.1016/j. jclepro.2020.121781

39. Zhou J, Ye G, van Breugel K (2016) Cement hydration and microstructure in concrete repairs with cementitious repair materials. Constr Build Mater 112:765-772. https://doi.org/10.1016/j.conbuildmat.2016.02.203

\section{Publisher's Note}

Springer Nature remains neutral with regard to jurisdictional claims in published maps and institutional affiliations.

\section{Submit your manuscript to a SpringerOpen ${ }^{\circ}$ journal and benefit from:}

- Convenient online submission

- Rigorous peer review

- Open access: articles freely available online

- High visibility within the field

- Retaining the copyright to your article

Submit your next manuscript at $\boldsymbol{\nabla}$ springeropen.com 